\title{
Cooperation or conflict over child health surveillance? Views of key actors
}

\author{
Stephen Gillam, Myer Glickman, Gillian Boyle, Caroline Woodroffe
}

\begin{abstract}
Objective-To describe the views of general practitioners, health visitors, and clinical medical officers on child health surveillance, recent changes, perceptions of each other's roles, and attitudes to audit.
\end{abstract}

Design-Postal questionnaire survey.

Setting-Three health districts in North West Thames health region.

Subjects-All 602 general practitioners, 272 health visitors, and 42 clinical medical officers in these districts.

Main measures-Attitudes to and perceptions of child health surveillance and audit. Questionnaires were completed by 440 general practitioners (response rate $73 \%), 164$ health visitors $(60 \%)$, and 39 clinical medical officers $(93 \%)$.

Results-Attitudes to child health surveillance were less positive among general practitioners than health visitors or clinical medical officers. Few respondents agreed that child health surveillance was a cost effective use of general practitioners' time (general practitioners $28 \%$, 113/407; health visitors $28 \%, 40 / 145$; clinical medical officers $39 \%, 15 / 39$ ) and most thought that health visitors should carry out more of the doctors' examinations $(68 \%, 262 / 387 ; 65 \%, 89 / 136 ; 66 \%$, $25 / 38)$. General practitioners thought that clinical medical officers were less supportive than other relevant groups of their doing more child health surveillance. Most $(72 \%, 105 / 146)$ health visitors thought that the 1990 contract had reduced parental choice of where to attend for child health surveillance. General practitioners were less enthusiastic than health visitors about most forms of clinical audit.

Conclusions-Despite reservations about the impact of recent changes all groups were willing to explore innovative ways of delivering child health surveillance.

Implications-There is scope for health visitors to increase their responsibilities and for more varied relationships between general practitioners and community child health doctors.

(Quality in Health Care 1993;2:83-86)

\section{Introduction}

Major changes are taking place in the way child health surveillance is carried out. The recent report of the Joint Working Party on
Child Health Surveillance (Hall report) attempted to define those elements of a surveillance programme that seem to be effective in the light of current consensus. ${ }^{1}$ This has led to a reduction in the diversity of child health surveillance schedules in use across the United Kingdom. ${ }^{2}$ The revised edition of the Hall report makes explicit recommendations about the most appropriate division of work between doctors and health visitors, although not between general practitioners and clinical medical officers, at each stage of the recommended surveillance programme.

In the face of these rationalising influences, other developments have increased the difficulties district health authorities face planning child health services. Under the terms of their new contract general practitioners receive a supplement for each registered child under the age of 5 years for whom they carry out developmental surveillance. ${ }^{3}$ The proportion of general practitioners (and practices) offering surveillance programmes has increased substantially (Department of Health, personal communication).

Responsibility for the clinical components and monitoring of surveillance is therefore shared between the district health authorities and family health services authorities (FHSAs). However, the creation of internal markets and rapidly changing organisational structures have rendered the collection and sharing of information needed to monitor child health surveillance more difficult. Community units face growing competition from other providers, both community units and general practitioner fundholders, particularly with the extension of fundholding to cover community services in April $1993 .^{4}$ These developments may not be consistent with policies favouring parental choice. ${ }^{5}$

As a result of the greater fragmentation of child health services closer collaborative links between the health professionals centrally involved in child health surveillance are required. The positions of these professionals contrast with each other. General practitioners have an expanding role whereas clinical medical officers have been declining in numbers for 20 years, and their traditional responsibilities in child health have been steadily eroded. The position of health visitors is less clear. The Health Visitors' Association has sought a prominent, more specialised role in child health surveillance. ${ }^{6}$ Hitherto, this has been resisted by the medical profession, and 
there is no generally accepted model for the location of health visitors in district structures. ${ }^{7}$ However, the recent changes are likely to result in their closer working relationship with general pracitioners.

Given this degree of uncertainty and the professional insecurities of key actors, it is not surprising that audit and monitoring systems have yet to be established in many districts. As part of a project seeking to establish multidisciplinary audit, this paper describes the views of general practitioners, health visitors, and clinical medical officers on child health surveillance; recent changes; perceptions of each other's roles, and attitudes to audit.

\section{Methods}

Three health districts in the North West Thames region were chosen to represent a range of socioeconomic characteristics of practitioners and their patients. Parkside is an urban district including severely deprived areas, Barnet is a more varied, suburban district, and South Bedfordshire is largely rural. Three anonymous surveys were carried out between July and December 1991. Questionnaires were sent to all 602 general practitioners (in 319 practices), 272 health visitors, and 42 clinical medical officers (including senior clinical medical officers) in the three districts, using lists provided by the FHSAs and community units. FHSAs also provided data on general practitioners' age and sex, size of practice, and inclusion on the child health surveillance list. Non-respondents were sent one reminder. These questionnaires sought from all respondents details of their participation in child health surveillance, relevant training and experience, and views on the organisation and effectiveness of child health surveillance. In addition, general practitioners and health visitors were asked for their views on audit of child health surveillance. Respondents gave their views on a 5 point scale from "definitely yes" to "definitely no." The proportion described here as supporting a statement replied "definitely yes" or "probably yes."

\section{Results}

Questionnaires were returned by $440 / 602$ $(73 \%)$ general practitioners, 164/272 (60\%) health visitors, and $39 / 42$ (93\%) clinical medical officers. More of the general practitioners who were providing child health surveillance replied than those who were not $(82 \%, 257 / 313$ v 64\%, 185/289 (95\% confidence interval for difference $11 \%$ to $25 \%$ )); the likely effect is to overestimate favourable attitudes to child health surveillance for all general practitioners taken together.

Data provided by the FHSAs showed that $52 \%(313 / 602)$ of general practitioners were undertaking child health surveillance; $57 \%$ (181/319) of practices had at least one partner on the child health surveillance list. Female doctors were twice as likely to provide child health surveillance as male doctors; those doctors undertaking child health surveillance tended to be younger and in larger practices; doctors with paediatric training were three times more likely to provide child health surveillance.

Of the health visitors responding, $56 \%$ $(92 / 164)$ participated in child health surveillance with one or more general practices. The majority of all health visitors felt that their workload in child health surveillance had not changed since the introduction of the 1990 general practice contract, but $36 \%(35 / 96)$ of those working in general practice and $12 \%(8 / 68)$ of the others said their workload had increased $(95 \%$ confidence interval for difference $13 \%$ to $35 \%)$. Only $39 \%(64 / 164)$ of all health visitors had noted changes in their working routine as a result of the new contract.

Only $8 \%(3 / 39)$ of the clinical medical officers were providing child health surveillance exclusively at secondary level (that is, after referral); 97\% (38/39) received referrals from health visitors, and $46 \%$ (18/39) received referrals from general practitioners.

ATTITUDES TO CHILD HEALTH SURVEILLANCE Although the views of health visitors and clinical medical officers on child health surveillance were broadly similar, general practitioners' perceptions were less positive (table 1). General practitioners who provided child health surveillance expressed more favourable views than those who did not. Only two thirds of all general practitioners regarded child health surveillance as enjoyable to do and a similar proportion thought that there was too much paperwork. Only a small proportion ( $28 \%$ to $39 \%$ ) of respondents in all groups thought that child health surveillance was a cost effective use of general practitioners' time.

PERCEPTIONS OF OTHER ROLES

About two thirds of respondents in all three groups felt that health visitors should carry out some of the examinations currently undertaken by doctors (table 2). Whereas $67 \%$ $(88 / 132)$ of health visitors thought that they could carry out all child health surveillance,

Table 1 Attitudes to child health surveillance. Figures are percentages (numbers)

\begin{tabular}{|c|c|c|c|c|c|}
\hline \multirow[t]{2}{*}{ Statement supported } & \multicolumn{3}{|c|}{ General practitioners } & \multirow{2}{*}{$\begin{array}{l}\text { Clinical medical } \\
\text { officers }\end{array}$} & \multirow[t]{2}{*}{ Health visitors } \\
\hline & On CHS list & Not on list & All & & \\
\hline $\begin{array}{l}\text { CHS builds up a good relationship with families } \\
\text { CHS is enjoyable to do } \\
\text { CHS is a cost effective use of general practitioners' time } \\
\text { CHS involves too much paperwork } \\
\text { CHS should ideally be done by general practitioners }\end{array}$ & $\begin{array}{l}91(218 / 240) \\
74(178 / 240) \\
33(80 / 239) \\
66(158 / 238) \\
85(203 / 240)\end{array}$ & $\begin{array}{l}86(147 / 172) \\
52(87 / 168) \\
20(33 / 168) \\
68(115 / 168) \\
67(118 / 175)\end{array}$ & $\begin{array}{l}89(365 / 412) \\
65(265 / 408) \\
28(113 / 407) \\
67(273 / 406) \\
77(321 / 415)\end{array}$ & $\begin{array}{l}97(37 / 38) \\
95(37 / 39) \\
39(15 / 39) \\
50(19 / 38) \\
51(20 / 39)\end{array}$ & $\begin{array}{l}94(138 / 147) \\
95(139 / 147) \\
28(40 / 145) \\
37(55 / 147) \\
19(27 / 144)\end{array}$ \\
\hline
\end{tabular}

CHS $=$ Child health surveillance. 
Table 2 Attitudes to increasing health visitors' role in child health surveillance. Figures are percentages (numbers)

\begin{tabular}{|c|c|c|c|c|c|}
\hline \multirow[t]{2}{*}{ Statement supported } & \multicolumn{3}{|c|}{ General practitioners } & \multirow{2}{*}{$\begin{array}{l}\text { Clinical medical } \\
\text { officers }\end{array}$} & \multirow[t]{2}{*}{ Health visitors } \\
\hline & On CHS list & Not on list & All & & \\
\hline $\begin{array}{l}\text { Health visitors should carry out some items of CHS } \\
\text { currently done by doctors }\end{array}$ & $69(157 / 226)$ & $65(105 / 161)$ & $68(262 / 387)$ & $66(25 / 38)$ & $65(89 / 136)$ \\
\hline $\begin{array}{l}\text { Health visitors should carry out all CHS and refer to a } \\
\text { doctor only when necessary }\end{array}$ & $24(57 / 236)$ & $41(67 / 163)$ & $31(124 / 399)$ & $32(12 / 38)$ & $67(88 / 132)$ \\
\hline
\end{tabular}

CHS = Child health surveillance.

referring children to a doctor only when necessary, less than a third of both groups of doctors agreed.

Most clinical medical officers were in favour of the attachment of clinical medical officers to practices, either to help with or to take on the main responsibility for child health surveillance. This interest was reciprocated by most general practitioners not providing child health surveillance $(54 \%, 92 / 172$ as help; $51 \%, 87 / 170$ as main responsibility) but not by those providing child health surveillance themselves $(36 \%, 86 / 238$ as help; $22 \%$, $52 / 237$ as main responsibility) (95\% confidence interval for difference $10 \%$ to $25 \%$, $22 \%$ to $36 \%$ respectively). There was strong support among clinical medical officers for greater involvement in aspects of child health other than child health surveillance - namely, special needs $(97 \%, 38$, respondents); child abuse $(87 \%, 34)$; acute paediatrics $(56 \%, 22)$; and other activities such as enuresis clinics, audiology, and child psychology.

The general practitioners thought that clinical medical officers were less supportive than other groups of their taking on more child health surveillance. Only $23 \%$ (95/413) general practitioners saw clinical medical officers as supportive, about half the number expecting support from consultant paediatricians $(43 \%, 180 / 417)$, FHSA managers $(51 \%, 212 / 413)$, and health visitors $(52 \%$, 216/417). The proportions of general practitioners seeing these groups as definitely unsupportive were $38 \%(158 / 413), 19 \%$ (79/417), 13\% (53/413), and 21\% (88/417) respectively.

Of all health visitors, $72 \% \quad(105 / 146)$ thought that the new general practitioner contract had reduced parental choice of where to attend for child health surveillance; $65 \%$ (95/146) thought it had created pressure on them to refer this work to general practitioners rather than clinical medical officers.

ATTITUDES TO AUDIT

General practitioners in all districts were considerably less enthusiastic than health

Table 3 Support for clinical audit. Figures are percentages (numbers)

\begin{tabular}{lcc}
\hline Form of audit supported & General practitioners & Health visitors \\
\hline Six monthly audit meetings & $45(185 / 410)$ & $82(116 / 142)$ \\
Joint clinics between general practitioner and & $33(133 / 407)$ & $78(110 / 142)$ \\
community child health staff & $89(370 / 415)$ & $97(143 / 147)$ \\
Feedback on adverse outcomes & $69(286 / 414)$ & $99(145 / 147)$ \\
Regular refresher courses & $38(157 / 411)$ & $71(104 / 147)$ \\
Self administered audit questionnaires & $12(49 / 409)$ & $24(33 / 139)$ \\
Have already undertaken any audit of CHS &
\end{tabular}

CHS = Child health surveillance. visitors about most forms of clinical audit (table 3). The clinical medical officers were not asked these questions. Automatic feedback about adverse outcomes was the most popular suggestion among general practitioners.

\section{Discussion}

Although attitudes to child health surveillance were mostly positive in all three groups, general practitioners' perceptions were more likely to be negative. Their greater irritation with the paperwork child health surveillance entails may reflect the large administrative burden they already carry after implementation of the 1990 contract. Other studies have suggested that a sizable minority of general practitioners will always be reluctant to undertake child health surveillance. ${ }^{8}$ Community child health clinics will continue to be needed for the patients of such practices and to maintain parental choice. Most health visitors thought that the new general practitioner contract had effectively reduced that choice. The difficulties of attempting to sustain dual provision are well illustrated in the recent history of family planning services.

New models of working therefore need to be developed to meet changing circumstances. Two thirds of clinical medical officers were interested in the idea of attachments to or direct employment by general practices. This interest was not reciprocated by all general practitioners, many of whom seemed to regard the clinical medical officers as unsupportive of the shift of child health surveillance to general practice. The clinical medical officers' responses did not justify this suspicion. Although clinical medical officers may feel uncertain about their long term job prospects, most respondents were enthusiastic about the other areas of work, such as special needs and child abuse, in which they may be required to specialise.

There is a tendency to think in terms of community clinic versus general practice based provision, but a new emphasis on cost effectiveness is stimulating more imaginative approaches to service provision. A large majority in all groups felt that child health surveillance was not a cost effective use of general practitioners' time. Two thirds of respondents felt that health visitors should carry out some elements of child health surveillance currently undertaken by doctors. Although doctors were predictably less enthusiastic about wholesale "takeover" by health visitors, further research may justify enlarging the health visitors' sphere of responsibility. The second edition of the Hall report has already done so. 
Uncertainty exists about the effectiveness of many elements of child health surveillance. ${ }^{7}$ The current recommended schedule will need to be modified in the light of subsequent evaluations. Audit is one way of continually updating practice. The general practitioners' lack of enthusiasm for audit is disappointing but unsurprising. The heavy emphasis on audit in the wake of Working for Patients ${ }^{9}$ had led to some disaffection among doctors. Cross disciplinary audit may help to alleviate this.

The creation of internal markets and the establishment of joint purchasing consortia are tending to blur organisational boundaries. The shift of child health surveillance into general practice demands new ways of configuring community child health services. These will require cooperative working relationships. This study suggests that the key groups involved are likely to meet that challenge.

We thank Professor Harry Stein for his part in the design of the study; Drs Rosemary Beardow, Marion Miles, Bridget Edwards, and Josephine Tew for help and advice; and the general practitioners, health visitors, and clinical medical officers of the three districts for their cooperation. $\mathrm{Mr}$ Glickman and Ms Woodroffe were funded by the Wolfson Foundation.

1 Hall DMB, ed. Health for all children: a programme for child health surveillance. Oxford: Oxford University Press, 1989.

2 Hall DMB, ed. Health for all children: a programme for child health surveillance. 2nd ed. Oxford: Oxford University Press, 1991.

3 Department of Health and Welsh Office. General practice in the National Health Service: a new contract. London: DoH, 1989.

4 National Health Service Management Executive. Guidance on the extension of the Hospital and Community Health
Services elements of the GP fundholding scheme from 1 April Services elements of the GP fundholding scheme from
1993. London: NHSME, 1992. (EL(92)48.)

5 Secretaries of State for Social Services, Wales, Northern Ireland, and Scotland. Promoting better health. London: HMSO, 1987. (Cm 249.)

6 Health Visitors Association. Project health: health promotion and the role of the school nurse in the school community. London: HVA, 1991.

7 Butler J. Child health surveillance in primary care: a critical review. London: HMSO, 1989.

8 Electoral Reform Ballot Services. Your choices for the future: a survey of GP opinion. UK report. London: BMA, 1992.

9 Secretaries of State for Health, Wales, Northern Ireland, and Scotland. Working for patients. London: HMSO, 1989. (Cmnd 555.) 